\title{
Methylene Dimethane Sulfonate
}

National Cancer Institute

\section{Source}

National Cancer Institute. Methylene Dimethane Sulfonate. NCI Thesaurus. Code C1162.

A member of the homologous series of dimethane sulphonic acid esters with alkylating properties. Methylene dimethane sulfonate alkylates DNA, resulting in interstrand DNA crosslinking, inhibition of DNA replication, disruption of the cell cycle, and cell death. 